American Journal of Applied Sciences 2 (13): 14-18, 2005

ISSN 1546-9239

(C) 2005 Science Publications

\title{
An Experimental Study of Petty Corrupt Behaviour in Small Decision Making Problems
}

\author{
Takemi Fujikawa \\ School of Economics and Finance, University of Western Sydney, Building 11, Room 33 \\ Campbelltown Campus, Locked Bag 1797, Penrith South DC, NSW 1797, Australia
}

\begin{abstract}
This research discusses small decision making problems and petty corruption as their practical applications with a structured economic experiment. One of examples of petty corruption considered includes demands for petty bribes by traffic officials followed by police. We examine that it is caused by subjective underweighting of rare events and its objective probabilities. This literature reports results of an experiment, which reveals that the subjects tended to subjectively underweight rare outcomes when they relied on feedback in small decision making problems. Underweighting of rare events lead the subjects to choose a risky option often, but not all the time, to maximise his/her expected utility. This tendency is the opposite of the overweighting of rare outcomes observed in mainstream big description-based decision problems. It is revealed that an individual petty corrupt behaviour is a consequence of the theoretically-optimal behaviour for the risk-seeking decision-maker. This is examined along with the expected utility model. The model well captures results of the experiment and it asserts that it is theoretically-optimal decision to do the petty corrupt behaviour (to receive petty bribes) occasionally for the risk-seeking official, who subjectively underweight rare event and its probability.
\end{abstract}

Key words: Bribe, corruption, expected utility, experiment, feedback

\section{INTRODUCTION}

Corruption is now major public concerns in many countries. It is recognised by a number of economists ${ }^{[1]}$ that corruption and bribery are major impediments to development. Corruption results in a lack of public confidence in democratic processes. It entrenches elites and slows economic growth and deepens economic inequality as money continues to trickle up. Corrupt behaviour, for example, bribery appears to lower not only the level of ethical consciousness but that of economical consciousness $^{[2]}$. It also undermines the society's economic activity ${ }^{[3]}$. Powpaka ${ }^{[4]}$ indicated that the intention to bribe positively correlates with an individual's attitude towards the need to succeed.

Notwithstanding grand corruption like that associated with the arms deal receives most media attention, petty corruption can be as damaging if left unchecked. In fact, in some countries (e.g., South Africa) petty corruption is the second most prevalent crime in those countries after housebreaking ${ }^{[5]}$. So long as one accepts relatively minor infractions of the law as acceptable behaviour, a gradual numbing of one's ethical sensitivity occurs over time ${ }^{[6]}$. Examples of the individual petty corrupt behaviour include billing personal calls to the company, padding expense accounts and cheating on time cards. Another example to be focused upon in this study relates to bribery by traffic officers. Some people offer a bribe to the traffic officer to avoid a speeding ticket. Although such a bribe is petty, it may affect one nation's attitudes towards larger ethical problems.
This research discusses small decision making problems and petty corruption as their practical applications. Small decision making problems are defined as consequential decision problems but each single choice is not very important because the options available to the decision-maker have similar expected values that may be quite small, so that little time and effort is typically invested in these problems ${ }^{[7,8]}$. My hypothesis is that the decision-maker subjectively underweights rare events and its probabilities in small decision making problems when the payoff structure of those events and probabilities is fully disclosed to the decision-maker. (Some previous research on small decision problems ${ }^{[9]}$ showed that the underweighting of rare events was observed under the experimental setting that the payoff structure of possible options was not disclosed to their subjects).

One of outstanding examples of petty corruption to be considered in this literature is demands for petty bribes by traffic officials followed by police. Ede et al. ${ }^{[10]}$ claimed that the traffic police may be more likely to engage in opportunistic corruption. This sort of petty corruption can be a subset of small decision problems. We examine that it is caused by underweighting of rare events and its probabilities. One considers the case, where sets of corrupt officials' past experiences imply that it is the common perception among the corrupt officials that the public largely interacts with traffic officials on the road where the actions of corrupt officials are difficult to be monitored and therefore penalised. In fact, very few $(2 \%)$ of all respondents in the survey conducted by Van Vuuren ${ }^{[5]}$ 
vowed they had ever tried to report a corrupt official to headquarters. Under this perception, the corrupt officials are likely to subjectively underweight the probability that their actions are being monitored and severely penalised by headquarters.

For instance, corrupt officials' past experiences may make the corrupt officials know that some public is likely to give petty bribes to the officials to facilitate services that can be withheld or denied. Usually tightwads will be processed but at the back of the line. In some countries, obnoxious tightwads who like to make loud speeches about corruption may find themselves with insurmountable visa irregularities. Receiving petty bribes for the corrupt officer is said to be like kissing in junior high school. Both parties (public and the official) must be willing. However, if the more one party (the officer) is brash or unwise and asks for bribes all the time, the more the risk is of being monitored by headquarters and severely rebuked his/her corrupt behaviour.

The expected utility model is presented in this literature to show that it is theoretically-optimal for the decision-maker to choose risky alternative often but not all the time within given periods. It follows that calibration of the models asserts that the risk-seeking decision-maker, who subjectively underweights rare outcomes and its objective probabilities, should choose a risky alternative for certain times during trials given to maximise his/her expected utility.

To check the appropriateness of the expected utility model, I conducted an economics experiment including small decision making problems. Results of the experiment reveal that, as the model asserts, the subjects tended to subjectively underweight rare outcomes when they relied on feedback in small decision making problems. Such underweighting of rare events led the decision-maker to choose a risky option often, but not always, to maximise his/her expected utility. This tendency is the opposite of the overweighting of rare outcomes observed in mainstream big description-based decision problems ${ }^{[11]}$.

One of the key arguments in this literature is that on the grounds that an individual petty corrupt behaviour can be regarded as a subset of small decision making problems, it is revealed that an individual petty corrupt behaviour is a consequence of the theoretically-optimal behaviour for the decision-maker with a particular riskseeking utility function. It reflects phenomena being occurred in these days that some individuals justify small violations as "unimportant," the examples of which include taking home office supplies, billing personal calls to the company, padding expense accounts and cheating on time cards. One rationalises the corrupt unethical behaviour in the examples through the thought that such behaviour is minor or insignificant cost. However, the thievery proceeds to more dramatic levels ${ }^{[12]}$.
Expected utility: This section proposes an expected utility model to show that the decision-maker with a particular risk-seeking (i.e., convex-to-origin) utility function should choose the risky option often but not all the time to maximise his/her expected utility in small decision making problems. Suppose the task for the decision-maker is a binary choice between the risky option with high expected value and the safe option with low expected value. It is theoretically-optimal to choose the risky option to some extent for the decisionmaker who has a risk-seeking utility function and subjectively underweights rare (risky) event and its objective probability. It follows that the decision-maker can maximise his/her expected utility by choosing the risky option for certain times within given periods. The situation shall be examined in the following.

Suppose that the decision-maker is fully disclosed the payoff structure of the following choice problem and is asked to choose one of the two alternatives, $\mathrm{H}$ and $\mathrm{L}$ at each round $\mathrm{t}(\mathrm{t}=1,2, \ldots, \mathrm{T})$.

Choice problem. Choose between:

$\begin{array}{lllll}\mathrm{H}: & \mathrm{x} & (\mathrm{p}) ; & 0 & (1-\mathrm{p}) \\ \mathrm{L}: & 1 & (1) & & \end{array}$

In the choice problem, for some $p \in(0,1)$ and $\mathrm{x}$ such that $\mathrm{px}>1$, the decision-maker gets $\mathrm{x} \in \mathrm{N}$ points with probability $\mathrm{p}$ and 0 point with probability (1-p) by choosing $\mathrm{H}$ : he/she gets one point for sure by choosing $\mathrm{L}$.

Here, we employ the following risk-seeking utility function, $\mathrm{u}(\mathrm{x})$, to examine that the decision-maker with this utility function should choose the risky option, $\mathrm{H}$, for certain times to maximise his/her expected utility Eq. (1):

$u(x)=\frac{\ln \left(x+R^{\theta}\right) e^{a x}-(x+a)^{\alpha}}{\left(x+R^{\eta}\right)^{\beta}+x^{\gamma}+x^{\delta}}$,

where, a, R, $\alpha, \beta, \gamma, \eta, \delta, \theta \in \mathrm{N}$ and $(\mathrm{du}(\mathrm{x}) / \mathrm{dx})>0$. The function, $\mathrm{u}(\mathrm{x})$, is a risk-seeking utility function for plausible parameters, that is, $\mathrm{u}(\mathrm{x})$ is the convex-toorigin utility function. For convexity of $\mathrm{u}(\mathrm{x})$, we expect that $\mathrm{u}(\mathrm{x})$, exhibits increasing marginal utility of payoff. This follows the derivative of $u(x)$ is positive. Then, we assume that marginal utility is positive and raise the following assumption in regard to the slope of marginal utility, the second derivative of $u(x)$ Eq. (2):

$$
\frac{\mathrm{d}^{2} \mathrm{u}(\mathrm{x})}{\mathrm{dx}^{2}}>0
$$

We now explain that the decision-maker with $\mathrm{u}(\mathrm{x})$, who subjectively underweights rare event and its objective probability, should choose $\mathrm{H} \mathrm{t}^{*}\left(0<\mathrm{t}^{*}<\mathrm{T}\right)$ times to maximise his/her expected utility in the choice problem above. Let $\mathrm{V}(\mathrm{m})$ be the expected utility the decision-maker, who subjectively underweights an objective probability, $\mathrm{p}$, to $\mathrm{p}<\mathrm{p}$, acquires when choosing $\mathrm{H} \mathrm{m}(0 \leq \mathrm{m} \leq \mathrm{T})$ times in the choice problem Eq. (3): 
$\mathrm{V}(\mathrm{m})=\sum_{\mathrm{k}=0}^{\mathrm{m}}\left[{ }_{\mathrm{m}} \mathrm{C}_{\mathrm{k}} \underline{\mathrm{p}}^{\mathrm{k}}(1-\underline{\mathrm{p}})^{\mathrm{m}-\mathrm{k}} \mathrm{u}(\mathrm{xk})\right]$,

where, $\mathrm{k}$ is the number of the highest payoff of $\mathrm{H}$ realised.

Experimental design: A computerised economics experiment on small decision making problems was conducted at Kyoto Sangyo University Economic Experiment Laboratory (KEEL). (The computer programme for the experiment was made by the author in Microsoft Visual Basic and is available from him) Forty-two undergraduates joined the experiment as paid subjects and they were all volunteers noticed by a mimic board on KEEL portal. The subjects received the written instruction which was read aloud and they were given an opportunity to ask questions individually before each experiment. (The written instruction is available in Appendix that is available upon request.) The instruction included explanations of computer screens and experimental procedure for consolidation of the experiment. At the conclusion of the experiment, the subjects were paid individually and privately at a conversion rate of one point to 0.3 Yen ( 0.25 US cent) and received no initial (showing up) fee.

The subjects were confronted with the choice problem below, which included 400 rounds with an immediate feedback. The experiment was conducted under the condition that each subject was fully disclosed the exact payoff structure and number of rounds to be performed.

Choice problem. Choose between:

\section{H: 32 points with probability $0.1 ; 0$ otherwise}

L: 3 points with probability 1

For example, by choosing $\mathrm{H}$, the subject got 32 points with probability 0.1 and zero point with probability 0.9 .

The subjects were instructed to operate a "computerised money machine" in the experiment. The task for the subjects was to choose one of two marked buttons shown in Fig. 1 for 400 times on which corresponding payoffs and its objective probabilities were appeared. The money machine provided the subjects with binary types of feedback immediately following each choice: (1) the payoff for the choice that appeared on the screen for the duration of one secondand (2) an update of an accumulating payoff counter, which was constantly displayed.

The average proportions of $\mathrm{H}$ choices (choiceH) throughout 400 rounds are 0.4 . It follows that the subjects, on average, chose H only 160 (40\%) out of 400 times. It implies deviations from maximisation. We see that there were substantial differences in choiceH among the subjects. (The choiceH for each subject is contained in Appendix that is available upon request). Figure 2 illustrates choiceH in blocks of 50 trials to facilitate an efficient summary of the large set of the data.

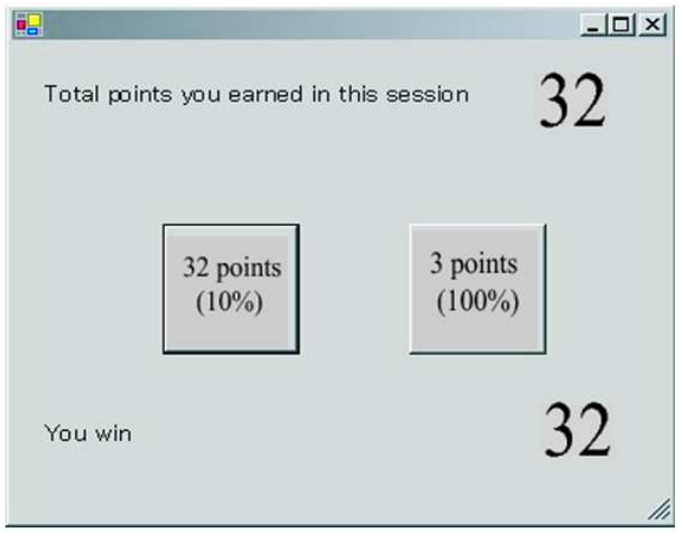

Fig. 1: The computerised money machine

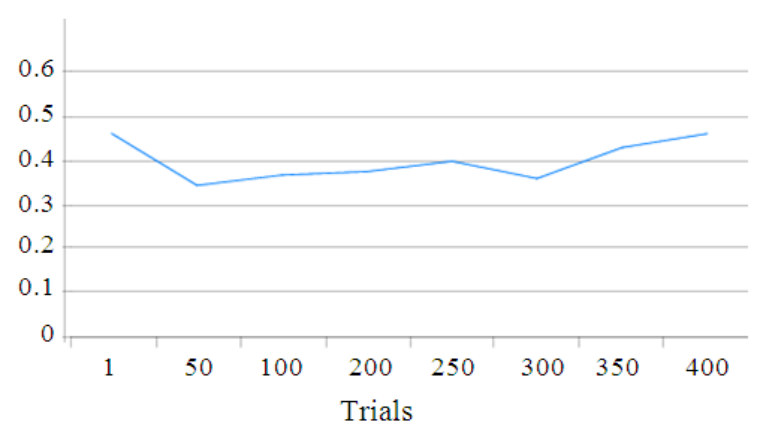

Fig. 2: choiceH

One implication of the tendency above is that the subjects subjectively underweighted the rare event, that is, the outcome of " 32 " and its objective probability, 0.1 at the beginning of the experiment. Note that L stochastically dominated $\mathrm{H}$ if the subjects subjectively underweighted the objective probability, 0.1 , to any $\mathrm{p} \in 0,1]$ such that 32 $\mathrm{p}<3$. In the event of understanding the objective probability of getting 32 points, the subjects should choose L for many times to maximise their expected payoff as they had behaved so in the experiment. (I in this literature assume that the rational decision-maker should make his/her decision to maximise expected utility. This rationality assumption has been widely accepted by a number of mainstream research about uncertainty ${ }^{[13]}$ ). If the subjects had subjectively overweighted or never subjectively evaluated the rare event and its objectively probability, $\mathrm{H}$ should have been chosen more, revealing expected utility maximisation.

Another implication is concerned with the effect of the expectation of playing the gambles repeatedly. It may follow that the subjects behaved in accordance with the process of "adaptive learning." Underweighting of the rare event in small decision making problems is the consequence of this expectation, whereas some previous research $^{[11]}$ exhibited that this expectation increased 
maximisation in big description-based decision making problems. As also discussed in Barron and Erev ${ }^{[7],}$ the low maximisation rates observed in the current experiment argue that experience with repeated choice in small decision making problems may have different effects to big description-based decision making problems.

Expected utility analysis: This section conducts an expected utility analysis to show that it is the theoretically-optimal behaviour for the decisionmaker in the experiment to choose $\mathrm{H}$ for specified times out of 400 times. The decision-maker is assumed to be risk-seeking and his/her utility function, denoted by $\hat{\mathrm{u}}(\mathrm{x})$, is the convex-to-origin utility function, which is obtained from $\mathrm{u}(\mathrm{x})$ by setting such parameters that $\mathrm{a}=0.005, \mathrm{R}=10, \alpha=4, \beta=3, \gamma=2, \delta=1, \theta=10$ and $\eta=2$. For convexity of $\hat{\mathrm{u}}(\mathrm{x})$, we expect that the utility function, $\hat{u}(\mathrm{x})$, exhibits increasing marginal utility of payoff. This follows the derivative of $\hat{u}(x)$ is positive. Hence the utility function to be employed is Eq. (4):

$\hat{\mathrm{u}}(\mathrm{x})=\frac{\ln \left(\mathrm{x}+10^{10}\right) \mathrm{e}^{0.005 \mathrm{x}}-(\mathrm{x}+0.005)^{4}}{\left(\mathrm{x}+10^{2}\right)^{3}+\mathrm{x}^{2}+\mathrm{x}}$,

where Eq. (5):

$$
\frac{\mathrm{du}(\mathrm{x})}{\mathrm{dx}}>0
$$

And:

$$
\frac{\mathrm{d}^{2} \hat{\mathrm{u}}(\mathrm{x})}{\mathrm{dx}^{2}}>0
$$

Recall that in the current experiment, the subject was fully disclosed the payoff structure of the following choice problem and is asked to choose one of the two alternatives, $\mathrm{H}$ and $\mathrm{L}$ at each round $\mathrm{t}(\mathrm{t}=1,2, \ldots, 400)$. In the choice problem, the subject gets 32 points with probability 0.1 and zero point with probability 0.9 by choosing $\mathrm{H}$ : he/she gets three point for sure by choosing $\mathrm{L}$.

Let $\hat{\mathrm{I}}(\mathrm{m})$ be the expected utility the decision-maker acquires when choosing $\mathrm{H} \mathrm{m}(0 \leq \mathrm{m} \leq 400)$ times in the experiment. It can be obtained from $\mathrm{V}(\mathrm{m})$ by setting, $\mathrm{p}$ $=0.098$ and $\mathrm{x}=32$ and is given by Eq. (7):

$$
\hat{\mathrm{I}}(\mathrm{m})=\sum_{\mathrm{k}=0}^{\mathrm{m}}\left[{ }_{\mathrm{m}} \mathrm{C}_{\mathrm{k}}(0.098)^{\mathrm{k}}(0.002)^{\mathrm{m}-\mathrm{k}} \mathrm{u}(32 \mathrm{k})\right]
$$

where, $\mathrm{k}$ is the number of the highest payoff of $\mathrm{H}, 32$, realised.

Calibration of $\hat{\mathrm{I}}(\mathrm{m})$ reveals an optimal number of $\mathrm{H}$ for the expected utility maximising risk-seeking decisionmaker with $\hat{\mathrm{u}}(\mathrm{x})$, who subjectively underweights an objective probability of the outcome "32" to 0.098. Figure 3 and 4 show $\hat{\mathrm{u}}(\mathrm{x})$ and $\hat{\mathrm{I}}(\mathrm{m})$, respectively.

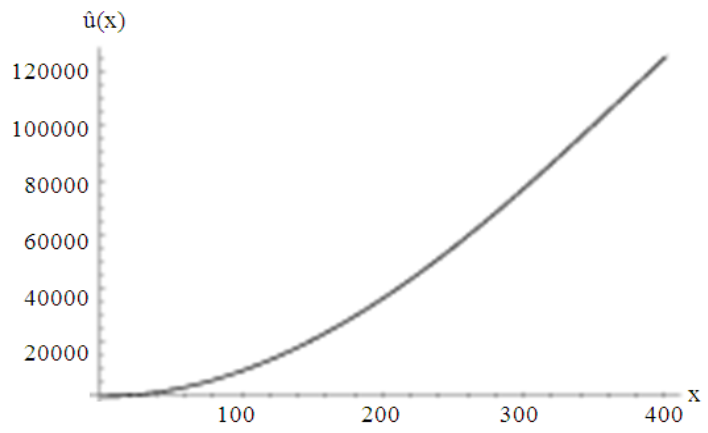

Fig. 3: The risk-seeking utility function, $\hat{\mathrm{u}}(\mathrm{x})$

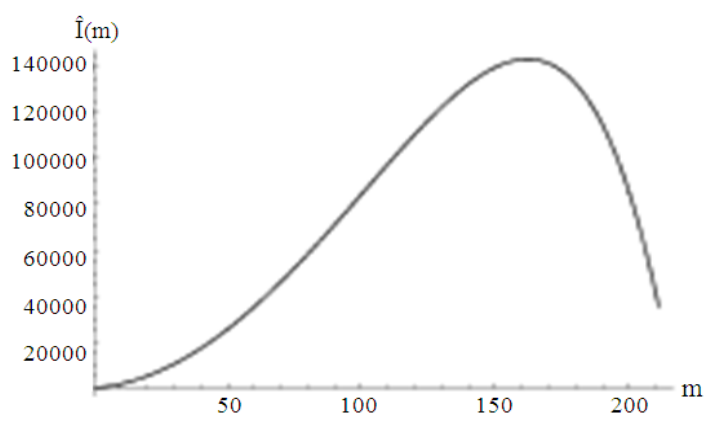

Fig. 4: Expected utility, $\hat{\mathrm{I}}(\mathrm{m})$

As shown in Fig. 4, $\hat{\mathrm{I}}(\mathrm{m})$ has its maximum at $\mathrm{m}=161$ for $0 \leq \mathrm{m} \leq 400$. It follows that the decision-maker can maximise his/her expected utility by choosing $\mathrm{H} 161$ out of 400 times in the choice problem. The above calibration well captures the subjects' behaviour in the current experiment in which they, on average, chose $\mathrm{H}$ 160 times. One implication of the subjects is concerned that they subjectively underweighted an objective probability of getting 32 points in the experiment, 0.1 , to 0.098. Then the subjects chose H 160 times, on average, to maximise their expected utility.

An application to the petty corrupt behaviour: The discussion above maintains that in a particular situation, the decision-maker can maximise his/her expected utility by choosing the rare risky option for certain times within given periods, when the decision-maker confronts with both the risky and the safe option in small decision making problems. We apply this discussion to the serious problems of an individual official's petty corrupt behaviour such as the traffic official's receiving petty bribes. It is on the grounds that such a petty corrupt behaviour can be regarded as a subset of small decision making problems.

The expected utility analysis carried out above reveals that an individual official's petty corrupt behaviour is the consequence of the risk-seeking official's theoreticallyoptimal decision. It is theoretically-optimal to receive petty bribes, occasionally, for the corrupt official who has a particular risk-seeking utility function $(\hat{\mathrm{u}}(\mathrm{x}))$ and 
subjectively underweights rare (risky) event and its objective probability, that is, the event of being monitored and penalised the petty corrupt action. It follows that in order to maximise his/her expected utility the corrupt official tends to receive petty bribes, sporadically, with risks of being monitored and arrested by headquarters. As observed in the current experiment, in a likely situation, an individual can maximise his/her expected utility by choosing the rare risky option for certain times within given periods, if provided both the safe option (i.e., not to receive bribes) and the risky option (i.e., to receive bribes and being penalised).

\section{CONCLUSION}

This research has discussed small decision making problems and petty corruption as their practical applications. One of outstanding examples of petty corruption considered includes demands for petty bribes by traffic officials followed by police. Traffic police may be more likely to engage in opportunistic corruption. This sort of petty corruption can be a subset of small decision making problems. We have examined that it is caused by underweighting of rare events and its probabilities. One considers the case, where sets of the corrupt officials' past experiences imply that it is the common perception among those officials that the public largely interacts with the traffic officials on the road where the actions of corrupt officials are difficult to be monitored and therefore penalised. Under this perception, corrupt officials are likely to subjectively underweight the probability that their actions are being monitored and severely penalised by headquarters.

This literature has reported results of the economics experiment including small decision making problems. The results revealed that the subjects tended to subjectively underweight rare outcomes when they relied on feedback in small decision making problems. Such underweighting of rare events led the decisionmaker to choose a risky option often, but not all the time, to maximise his/her expected utility. This tendency is the opposite of the overweighting of rare outcomes observed in mainstream big description-based decision problems. One of the key findings is that it is revealed that an individual petty corrupt behaviour is a consequence of the theoretically-optimal behaviour for the risk-averse decision-maker. It reflects phenomena being occurred in these days that some individuals justify small violations as "unimportant."

For an investigation on petty corrupt behaviour, we have employed the expected utility model. The model well captures the actual decision-makers behaviour in the experiment. The calibration of the model insists that it is theoretically-optimal decision to do the petty corrupt behaviour (to receive petty bribes) occasionally for the official with a riskseeking utility function, who subjectively underweight rare event and its objective probability.

\section{REFERENCES}

1. Gordon, K. and M. Miyake, 2001. Business approaches to combating bribery: A study of codes of conduct. J. Bus. Ethics, 34: 161-173. DOI: 10.1023/A:1012517622479

2. Ferrell, O.C., J. Fraedrich and L. Ferrell, 2000. Business Ethics: Ethical Decision Making and Cases. 4th Edn., Houghton Mifflin, Boston, ISBN10: 0395959535 , pp: 396.

3. Longenecker, J.G., J.A. McKinney and C.W. Moore, 1988. The ethical issue of international bribery: A study of attitudes among U.S. business professionals. J. Bus. Ethics, 7: 341-346. DOI: 10.1007/BF00382536

4. Powpaka, S., 2002. Factors affecting managers' decision to bribe: An empirical investigation. J. Bus. Ethics, 40: 227-246. DOI: 10.1023/A:1020589612191

5. Van Vuuren, H., 2004. Small bribes, big challenge: Extent and nature of petty corruption in South Africa. SA Crime Q., 9: 11-16. http://connection.ebscohost.com/c/articles/5727605 2/small-bribes-big-challenge-extent-nature-pettycorruption-south-africa

6. Baack, D., C. Fogliasso and J. Harris, 2000. The personal impact of ethical decisions: A social penetration theory. J. Bus. Ethics, 24: 39-49. DOI: 10.1023/A:1006016113319

7. Barron, G. and I. Erev, 2003. Small feedbackbased decisions and their limited correspondence to description-based decisions. J. Behav. Decis. Mak., 16: 215-233. DOI: $10.1002 / \mathrm{bdm} .443$

8. Fujikawa, T., 2005. Can the Bayesian updating model explain decision making in small feedbackbased decision problems? Proceedings of the Presented at Australasian Business and Behavioural Sciences Association Conference, (SAC' 05), Cairns, Australia, pp: 464-475.

9. Erev, I. and G. Barron, 2005. On adaptation, maximization and reinforcement learning among cognitive strategies. Psychol. Rev., 112: 912-31. PMID: 16262473

10. Ede, A., R. Homel and T. Prenzler, 2002. Reducing complaints against police and preventing misconduct: A diagnostic study using hot spot analysis. Australian New Zealand J. Criminol., 35: 27-42.

http://www.ingentaconnect.com/content/aap/anzjc/ 2002/00000035/00000001/art00002?crawler=true

11. Kahneman, D. and A. Tversky, 1979. Prospect theory: An analysis of decision under risk. Econometrica, 47: 23-53. http://www.jstor.org/discover/10.2307/1914185?ui $\mathrm{d}=2129 \&$ uid $=3738832$ \&uid $=2 \&$ uid $=70$ \&uid $=4 \&$ si $\mathrm{d}=21102371360681$

12. Cederblom, J. and C.J. Dougherty. 1990. Ethics at Work. Belmont. Wadsworth.

13. Becker, G.S. and K.M. Murphy, 1988. A theory of rational addiction. J. Political Econ., 96: 675-700. http://www.jstor.org/stable/1830469 